\title{
Effectiveness of Dimethyl Fumarate in Real-World Clinical Practice and Strategy to Minimize Adverse Effects and Use of Healthcare Resources
}

This article was published in the following Dove Press journal: Patient Preference and Adherence

\author{
Ana Rodríguez-Regal ${ }^{\prime}$ \\ Laura Ramos-Rúa ${ }^{2}$ \\ Luis Anibarro-García (iD ${ }^{3}$ \\ Ana María Lopez Real ${ }^{4}$ \\ María del Campo Amigo- \\ Jorrín' \\ 'Department of Neurology, Complejo \\ Hospitalario Universitario de Pontevedra \\ (CHUP), Pontevedra, Spain; ${ }^{2}$ Department \\ of Neurology, Hospital Público de \\ Monforte, Lugo, Spain; ${ }^{3}$ Department of \\ Internal Medicine, Complejo Hospitalario \\ Universitario de Pontevedra (CHUP), \\ Pontevedra, Spain; ${ }^{4}$ Department \\ OfNeurology, Complejo Hospitalario \\ Universitario de Coruña (CHUAC), La \\ Coruña, Spain
}

Background: Dimethyl fumarate (DMF) has shown efficacy in reducing relapse rates in patients with multiple sclerosis (MS). However, associated adverse effects (AE) such as gastrointestinal (GI) AE, flushing and lymphopenia are the main cause of treatment discontinuation. The aim of this study was to evaluate the effectiveness of DMF, and to assess strategies to reduce treatment discontinuation rates in routine clinical practice.

Patients and Methods: Ninety patients started DMF treatment between August 2015 and February 2020. Prior to DMF therapy, patients received written information regarding treatment and the management of $\mathrm{AE}$, along with medical prescriptions. Clinical and analytical data were collected at clinical visits performed at least 6-monthly, and disease progression was evaluated by brain magnetic resonance imaging (MRI).

Results: Prior to DMF, $78.7 \%$ of patients had an annualized relapse rate (ARR) of 1.07 (range: 1-3) and median Expanded Disability Status Scale (EDSS) score of 1.0 (range: 0-2). At final follow-up, ARR and median EDSS scores were significantly reduced to 0.09 (range: $0-2 ; \mathrm{p}<0.001$ ) and 0 (range: $0-1.625 ; \mathrm{p}<0.001$ ), respectively. Just over one quarter of patients with brain MRI (26.8\% of 71 patients) showed improvement in disease activity based on MRI evaluation. Lymphopenia was associated with previous treatment lines $(p=0.042)$ and longer disease duration $(p=0.032)$. A total of twelve patients abandoned DMF treatment, mainly due to lymphopenia $(7.9 \%)$, but none did it because of GI AE or flushing.

Conclusion: In our series, DMF showed high clinical and radiological efficacy. Providing patients with complete information prior to treatment on the management of associated $\mathrm{AE}$ helps them to better understand what to expect, improves tolerance and reduces clinical and telephone consultations, which may help to reduce the use and cost of healthcare resources. Keywords: multiple sclerosis, dimethyl fumarate, annualized relapse rate, adverse effects, clinical practice

\section{Introduction}

Multiple sclerosis (MS) affects approximately 2.5 million people worldwide, and is the most common demyelinating disease in young adults. ${ }^{1,2}$ In Spain, recent epidemiological studies have confirmed the progressive increase in its prevalence in recent decades, which is as high as 80-180 cases per 100,000 inhabitants, with a higher incidence among women. ${ }^{3} \mathrm{MS}$ is an immune-mediated inflammatory disorder in which the immune cells themselves induce demyelination and axonal damage in the central nervous system, which is the main cause of disability. Several
Correspondence: María del Campo Amigo-Jorrín

Complejo Hospitalario Universitario de Pontevedra (CHUP), Avda. Eduardo Pondal 4-6G, Pontevedra 36003, Spain, Tel +34619583752

Email mcampoamigo@gmail.com
Patient Preference and Adherence 2021:15 149-158 
pathological mechanisms underlie the clinical manifestations of MS, including inflammation, demyelination, and axonal degeneration. ${ }^{4,5}$ However, the precise cause of MS remains unknown.

Various disease-modifying therapies (DMTs) with varying efficacy and safety and different recommendations for use are available. ${ }^{6,7}$ Unfortunately, the therapeutic response is suboptimal in many patients. ${ }^{8,9}$ The approval of oral therapies such as fingolimod (FTY), dimethyl fumarate (DMF) and teriflunomide (TRF), among others, was a step forward in the treatment of MS that introduced new mechanisms of action against the disease and a more convenient route of administration for the patient. ${ }^{10-12}$ New drugs are now appearing in the therapeutic repertoire, and new oral therapies are in clinical development. ${ }^{13-15} \mathrm{At}$ present, early initiation of treatment with any DMT in patients with relapsing-remitting multiple sclerosis (RRMS) is currently recommended even before the appropriate therapeutic choice is clearly defined. ${ }^{16,17}$

Oral delayed-release DMF was approved in the United States and Europe in 2013 and 2014, respectively, for the treatment of RRMS, given its anti-inflammatory and cytoprotective effects. ${ }^{18,19}$

Two Phase III trials demonstrated the efficacy of DMF in reducing the annualized relapse rate (ARR) by approximately $50 \%$. Radiological improvement was also observed in terms of both a reduction in the number of new or enlarging T2-hyperintense lesions and of gadoliniumenhancing lesions. ${ }^{20,21}$ Results of extension studies have shown that continued treatment with DMF is safe and provides a sustained benefit over time..$^{22-24}$

The use of DMF in real-world clinical practice has confirmed its effectiveness in reducing clinical relapses. Its inflammatory effect is very similar to that of FTY and better than that of interferon $\beta$-1a (INF $\beta$-1a), glatiramer acetate (GA) and TRF. ${ }^{25,26}$ Cost-effectiveness studies have concluded that DMF is the drug associated with the greatest reductions in hospital stay costs per patient compared to IFNß-1a, GA, TRF or FTY. ${ }^{27}$

However, DMF has a higher dropout rate during the initial months of treatment due to adverse effects (AE), mainly gastrointestinal (GI) effects and flushing. ${ }^{28}$ Lymphopenia is one of the most concerning AE that may lead to DMF withdrawal in up to $7 \%$ of patients, as reported in several real-life studies. Prior monitoring of absolute lymphocyte counts (ALC) currently provides an effective means for early identification of patients at higher risk of developing severe lymphopenia. ${ }^{29}$ The need to improve therapeutic adherence has prompted the search for consensus guidelines on the optimal management of DMF-related GI events, aimed at reducing the likelihood of treatment interruption for this reason. ${ }^{30}$

The objective of this study was to evaluate the effectiveness of DMF in real-world clinical practice, and to assess therapeutic strategies aimed at counteracting the impact of GI AE on therapeutic adherence.

\section{Methods}

\section{Patients and Study Design}

We conducted an observational retrospective study based on data collected during routine clinical practice to assess the efficacy and patient adherence to DMF in a real-life setting. A total of 90 patients from the Hospital Público de Monforte de Lemos (Lugo, Spain) and the Complejo Hospitalario Universitario de Pontevedra (CHUP; Pontevedra, Spain) diagnosed with RRMS who started treatment with DMF between August 2015 and February 2020 were selected; no other selection criteria were applied. Before starting treatment, all patients were provided with written and verbal guidelines to prevent and manage potential adverse effects. The information included the recommendation for co-administration of DMF with food, a guideline for escalating DMF administration, a description of the most common $\mathrm{AE}$ that might occur, and a prescription for medications for appropriate management of AE (Figure 1). The proposed posology for DMF was a starting dose of $120 \mathrm{mg}$ once a day (in the evening) for seven days (week 1); $120 \mathrm{mg}$ twice a day (morning and evening) for seven days (week 2); $120 \mathrm{mg}$ of DMF in the morning/240 $\mathrm{mg}$ in the evening for seven days (week 3) and finally, $240 \mathrm{mg}$ DMF twice a day (morning and evening) for week 4 and indefinitely. Follow-up consisted of an initial visit at which baseline patient characteristics were collected, including demographic variables (such as age and sex), and clinical variables that included time between disease onset and starting DMF, pretreatment ARR, Expanded Disability Status Scale (EDSS) scores, pre-DMF treatments, and baseline magnetic resonance imaging (MRI) performed in the month prior to initiation of DMF (Table 1).

Follow-up visits were scheduled every 6 months after starting DMF (or earlier, if the patient's clinical situation so required). Data on clinical and radiological disease activity were prospectively collected at each 6-monthly visit. Clinical activity was determined by the occurrence 


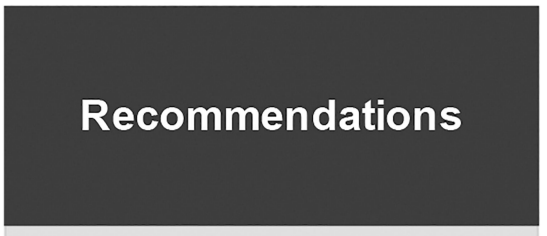

- Take your medication with food and a glass of water.

- If you forget a dose, you may take the missed dose if you leave at least 4 hours between the doses.

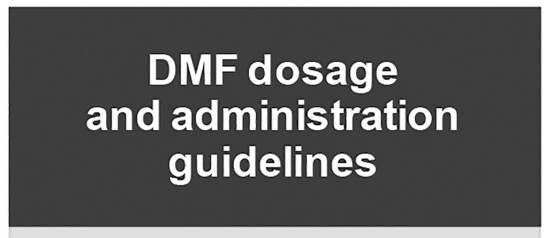

- Tecfider $\mathrm{a}^{\circledR} 120 \mathrm{mg}$ :

-0-0-1 week 1

- 1-0-1 week 2

-1-0-2 week 3

- Tecfidera ${ }^{\circledR} 240 \mathrm{mg}$ :

-1-0-1 week 4 and indefinitely
Management

of AEs

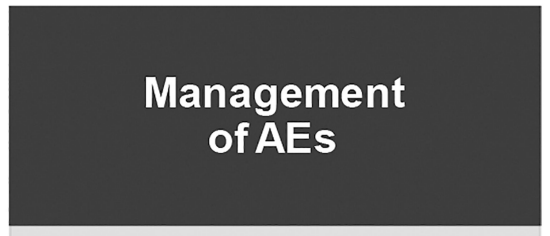

Abdominal pain:

- Omeprazole $20 \mathrm{mg}$ :

- 1-0-0

Nausea/vomiting:

- Domperidone oral solution $1 \mathrm{mg} / \mathrm{ml}$ :

- 1 to 2 spoons 30 minutes before Tecfidera $^{\circledR}$

Diarrhea:

- Loperamide $2 \mathrm{mg}$ :

- 1 capsule after each bowel movement

\section{Flushing:}

-A.A.S. $500 \mathrm{mg}$ :

- 30 minutes before taking Tecfidera ${ }^{\circledR}$

Figure I Information provided to the patient in writing prior to starting DMF (Tecfidera ${ }^{\circledR}$ ). Dose schedule $0-0-I$ represents I dose at the described concentration in the evening, daily; I-0-I represents two doses at the described concentration (in the morning and evening), daily; I-0-2 represents one dose at the described concentration in the morning and a double dose at the described concentration in the evening, daily.

of relapses requiring corticosteroid treatment, disability progression (EDSS), incidence of $\mathrm{AE}$ and laboratory data. Radiological activity was evaluated through brain MRI, and defined based on the number of gadoliniumenhancing lesions $\left(\mathrm{Gd}^{+}\right.$lesions $)$and/or new $\mathrm{T} 2$ hyperintense lesions after at least 12 months of continuous DMF treatment. These procedures continued throughout follow-up until the last visit at which the patient was receiving DMF, time of data analysis (April 2020) or the withdrawal of DMF for any reason. The presence of clinical activity ( $>1$ relapse that required corticosteroid treatment) or brain MRI activity (detection of $\geq 1$ new $\mathrm{Gd}^{+}$ lesions or $\geq 2$ new T2-hyperintense lesions) was considered therapeutic failure.

First, we assessed the proportion of patients who discontinued DMF during follow-up and the reasons for discontinuation. Factors that might affect the incidence of general or specific $\mathrm{AE}$ were analyzed using regression models. AE data collection included the appearance of flushing, GI symptoms, infectious, tumor or autoimmune complications, lymphopenia grade 3 (defined as a lymphocyte count $<0.5 \times 10^{9} / \mathrm{L}$ maintained for 6 months), and raised transaminases (AST/ALT $>2$ times normal values) among others. Finally, as criteria for clinical therapeutic efficacy, we analyzed ARR, MRI images, and the change in median EDSS score at the final visit and compared them to the patient's baseline situation. Disability worsening was defined as an increase in EDSS of 0.5 points, and improvement as a reduction of 0.5 points, with any of these changes sustained for at least for 6 months during follow-up. For MRI results, an absence or increase in the number of $\mathrm{Gd}^{+}$lesions and/or new T2-hyperintense lesions was assessed to determine changes in radiological activity at the end of data collection.

Phone calls and hospital visits for AE were recorded during follow-up. The study was carried out in accordance with the requirements set forth in the Declaration of 
Table I Baseline Characteristics of Study Patients at DMF Initiation

\begin{tabular}{|c|c|}
\hline Characteristics & $\begin{array}{l}\text { Total Patients } \\
(\mathrm{N}=90)\end{array}$ \\
\hline Age (years); mean (SD) & $39.4(11.3)$ \\
\hline \multicolumn{2}{|l|}{ Sex, (\%) } \\
\hline Women & 71.1 \\
\hline Men & 28.9 \\
\hline $\begin{array}{l}\text { Mean time since diagnosis (months), Pe } \\
\text { (SD); (minimum-maximum) }\end{array}$ & 68 (9.2); (I-409) \\
\hline $\begin{array}{l}\text { ARR by patient and year, preceding year } \\
\text { (minimum-maximum) }\end{array}$ & $1.07(I-3)$ \\
\hline Median EDSS (range) & $1.0(0-2)$ \\
\hline No previous treatment, $\mathrm{n}(\%)$ & $43(47.7)$ \\
\hline Other previous treatments, n (\%) & $47(52.2)$ \\
\hline Interferon beta-Ia & $22(24.4)$ \\
\hline Interferon beta-Ib & $16(17.7)$ \\
\hline Laquinimod & $\mathrm{I}(\mathrm{I} . \mathrm{I})$ \\
\hline Azathioprine & $\mathrm{I}(\mathrm{I} . \mathrm{I})$ \\
\hline Glatiramer acetate & $6(6,7)$ \\
\hline Teriflunomide & $\mathrm{I}(\mathrm{I} . \mathrm{I})$ \\
\hline \multicolumn{2}{|l|}{$\begin{array}{l}\text { Reason for discontinuing previous } \\
\text { treatment, } \mathbf{n}(\%)\end{array}$} \\
\hline Therapeutic failure & $32(35.5)$ \\
\hline $\mathrm{AE}$ & $14(15.5)$ \\
\hline Patient Initiative & $\mathrm{I}(\mathrm{I} . \mathrm{I})$ \\
\hline Brain MRI (Gd ${ }^{+}$lesions), n (\%) & $40(44.4)$ \\
\hline I lesion & $19(47.5)$ \\
\hline 2 lesions & $9(22.5)$ \\
\hline 3 lesions & $4(10)$ \\
\hline$\geq 4$ lesions & $7(17.5)$ \\
\hline Brain MRI (T2-hyperintense lesions), n (\%) & $90(100)$ \\
\hline$<10$ lesions & $13(14.4)$ \\
\hline I0-20 lesions & $25(27.7)$ \\
\hline$>20$ lesions & $52(57.8)$ \\
\hline
\end{tabular}

Abbreviations: $A E$, adverse effects; $A R R$, annualized relapse rate; Gd, gadolinium; $M R I$, magnetic resonance imaging; SD, standard deviation.

Helsinki (Fortaleza, October 2013) and current Spanish legislation on observational studies (Ministerial Order SAS/3470/2009) and personal data protection (Organic Law 3/2018, December 5). All patients signed informed consent to participate in the study, which did not entail any change in their care. The study was approved by the Galicia Ethics Committee (Comité Ético de Investigación con Medicamento de Galicia; CEIm-G).

\section{Statistical Analysis}

Statistical analysis was performed using SPSS software version 16.0. Qualitative variables were expressed as frequencies and percentages; quantitative variables were expressed as mean and standard deviation (SD), or as medians and interquartile ranges (IQR) for variables without normal distribution. Fisher's test or the Chi-square test was used to determine the association between qualitative variables. Normal distribution of the quantitative variables was tested using the Kolmogorov-Smirnov statistical test. The Student's $t$-test was used to examine the association between quantitative variables with normal distribution, while the Mann-Whitney or Wilcoxon test was used for the remaining variables. A $p$ value $<0.05$ was considered statistically significant. Finally, multivariate analysis of binary logistic regression was performed using the Intro method with variables that were significant or close to significance and clinically relevant in the univariate analysis.

\section{Results}

\section{Baseline Characteristics}

The mean age of the 90 patients was $39.4 \pm 11.3$ years, and $71.1 \%$ were women. DMF was the first treatment used in 43 patients $(47.7 \%)$, while the other 47 (52.2\%) had received at least 1 other drug before the study. In this second group, the most frequent reason for changing previous medication was treatment failure $(68 \%$ of patients), followed by AE (28.8\%). One patient discontinued treatment on his own initiative (Table 1).

Median progression on EDSS one year before starting DMF was 1 (range: 0-2). ARR in the year prior to starting DMF was 1.07 (minimum-maximum: 0-3; range: 1-2). Twenty patients $(22.2 \%)$ had an ARR of 0 while the other 70 patients $(78.7 \%)$ had at least one relapse (ARR: 1.07).

All patients underwent MRI prior to starting DMF (Table 1). T1 contrast-enhanced lesions were found in 40 patients $(44.4 \%$ ) (19 patients with 1 focus; 9 with 2 foci; 4 with 3 foci; and another 7 patients had 4 or more contrast-enhancing lesions). In the $\mathrm{T} 2$ sequence, fewer than 10 lesions were observed in 13 patients (14.4\%), while 25 patients $(27.7 \%)$ had between 10 and 20 lesions, and the remaining 52 patients (57.8\%) had more than 20 lesions. 
Table 2 Patient Characteristics at the End of Follow-Up

\begin{tabular}{|c|c|}
\hline Characteristics & $\begin{array}{l}\geq 6 \text { Months (Total } \\
\mathbf{N}=\mathbf{8 9} \text { ) }\end{array}$ \\
\hline Follow-up time (months); mean (SD) & $24(11.87)$ \\
\hline $\begin{array}{l}\text { ARR by patient and year (minimum- } \\
\text { maximum) }\end{array}$ & $0.09(0-2)$ \\
\hline $\begin{array}{l}\text { Patients relapsing during follow-up, } \\
\text { n (\%) } \\
\text { I relapse } \\
2 \text { relapses }\end{array}$ & $\begin{array}{l}6(6.7) \\
4(4.5) \\
2(2.2)\end{array}$ \\
\hline Median EDSS (range) & $0.0(0-1.625)$ \\
\hline $\begin{array}{l}\text { Change in EDSS, } \mathbf{n}(\%) \\
\text { Improvement } \\
\text { Worsening } \\
\text { No change }\end{array}$ & $\begin{array}{l}26(29.2) \\
6(6.7) \\
57(64)\end{array}$ \\
\hline Treatment discontinuation rate, $\mathbf{n}(\%)$ & $12(13.5)$ \\
\hline $\begin{array}{l}\text { Reason for discontinuation, } \mathbf{n}(\%) \\
\text { Therapeutic failure } \\
\text { Patient Initiative } \\
\text { Flushing/GI AE } \\
\text { Lymphopenia } \\
\text { Allergic reaction to DMF }\end{array}$ & $\begin{array}{l}3(3.4) \\
1(1.1) \\
0(0) \\
7(7.9) \\
I(1.1)\end{array}$ \\
\hline $\begin{array}{l}\text { Brain MRI (Gd }{ }^{+} / \mathbf{T} 2-\text { hyperintense } \\
\text { lesions), } \mathbf{n}(\%) \\
\text { Increase } \\
\text { Reduction } \\
\text { No change }\end{array}$ & $\begin{array}{l}71(79.7) \\
19(26.8) \\
19(26.8) \\
33(46.5)\end{array}$ \\
\hline Visits, calls, e-mails (not scheduled) & $2(2.2 \%)$ \\
\hline
\end{tabular}

Abbreviations: ARR, annualized relapse rate; $G I A E$, gastrointestinal adverse effects; DMF, dimethyl fumarate; Gd, gadolinium; MRI, magnetic resonance imaging; $\mathrm{SD}$, standard deviation.

\section{Monitoring and Effectiveness of DMF Treatment}

The characteristics of the disease course in patients treated with DMF are shown in Table 2. At the final data collection, 78 patients $(86.7 \%)$ were still receiving treatment with DMF, and the mean follow-up in these patients was 24 months (range: 6-36), with a minimum follow-up of 6 months in all patients. Follow-up periods pooled by months were as follows: $>36$ months, 34 patients; $>24$ months, 21 patients; $>18$ months, 12 patients; $>12$ months, 12 patients; and $>6$ months, 11 patients.

After starting DMF, 6 patients (6.7\%) relapsed during follow-up: 4 patients had a single relapse (4.5\%) and the remaining 2 patients had two relapses $(2.25 \%)$. Time to first relapse after DMF treatment initiation was 6 months for 2 patients, 12 months for 2 patients and 18 months for 2 patients.

Overall, $93 \%$ of treated patients were relapse-free. At the end of follow-up, a significant reduction in ARR from 1.07 (range: $1-3$ ) to 0.09 (range: $0-2 ; \mathrm{p}<0.001$ ) was observed.

There was also a significant reduction in median EDSS, from 1 (range: $0-2$ ) to 0 (range: 0-1.625; $\mathrm{p}<0.001)$. Twenty-six patients $(29.2 \%)$ showed improvement in the EDSS score, while $64 \%$ did not experience any change and $6.7 \%$ ( 6 patients) showed disability worsening. None of the study variables were significantly associated with an improvement in EDSS score. Changes in radiological activity were evaluated at the final visit. In total, $26.8 \%$ of patients with a follow-up MRI (71 patients) showed a reduction in the number of $\mathrm{Gd}^{+}$lesions and/or T2-hyperintense lesions, while $46.5 \%$ showed no significant changes and $26.8 \%$ of patients presented new $\mathrm{Gd}^{+}$ and/or T2-hyperintense lesions. Univariate regression analysis confirmed that an improvement in MRI outcomes was associated with younger age at baseline (33 vs 41.4 years; mean difference $=8.4 ; 95 \%$ CI: $2.7-14 ; \mathrm{p}=0.004$ ), lower median baseline EDSS ( 0.0 vs $1.75 ; \mathrm{p}=0.01)$, and previous ARR of $0(p=0.03)$. In the adjusted analysis, only a lower baseline EDSS was independently associated with improved follow-up MRI ( $p=0.03)$.

\section{Treatment Safety and Adverse Effects}

During follow-up, DMF was discontinued in 12 patients: 1 patient voluntarily discontinued treatment (without presenting any AE), 3 patients discontinued due to lack of therapeutic response, and $8(8.9 \%)$ due to $\mathrm{AE}$ (of these patients, 1 developed allergy to DMF and the remaining 7 presented grade 3 lymphopenia). One patient was discontinued after a positive pregnancy test. The infant was normal at birth, the mother did not have any relapses during treatment suspension, and DMF was restarted after delivery. Except for the patient who had an allergic reaction and the patient who voluntarily discontinued treatment, DMF was discontinued at or after the second 6-month visit (Table 2).

No discontinuation due to $\mathrm{GI} \mathrm{AE}$ or flushing was recorded. Telephone calls and hospital visits related to the appearance of $\mathrm{AE}$ involved only the patient with an allergic reaction and the pregnant patient.

Fifty-three patients (58.9\%) reported some AE during follow-up, of whom $51(96.2 \%)$ reported their event at the first scheduled visit (Table 3): 28 patients reported 
Table 3 Adverse Effects During Follow-Up

\begin{tabular}{|l|l|}
\hline Types of AE & Patients, n (\%) \\
\hline No AE & $37(41.1 \%)$ \\
\hline AE & $53(58.9 \%)$ \\
Flushing & $39(43.3 \%)$ \\
Gl & $34(37.7 \%)$ \\
Lymphopenia grade 3 & $7(7.7 \%)$ \\
Mild infections & $3(3.3 \%)$ \\
Allergic reactions & $\mathrm{I}(1.1 \%)$ \\
Elevated transaminases grade 2 & $\mathrm{I}(\mathrm{I} .1 \%)$ \\
\hline
\end{tabular}

Abbreviation: $A E$, adverse effects; GI, gastrointestinal.

a single $\mathrm{AE}$, while 17 patients reported $2 \mathrm{AE}$, and 8 patients reported $3 \mathrm{AE}$ (Figure 2). Flushing was the most frequent $\mathrm{AE}$, affecting 39 patients (43.3\%). GI discomfort was reported by 34 patients (37.7\%) including patients with more than one AE. Finally, 8 patients presented lymphopenia (8.9\%). Other AE collected were mild infections (3 patients), allergic reaction to DMF (1 patient) (exanthema, delayed type IV hypersensitivity reaction) and grade 2 transaminase elevation (1 patient). No tumor or other significant AE was detected during the follow-up period. Univariate analysis revealed that none of the variables analyzed was associated with the appearance of $\mathrm{AE}$ in general or with the appearance of specific AE, such as flushing or GI AE.

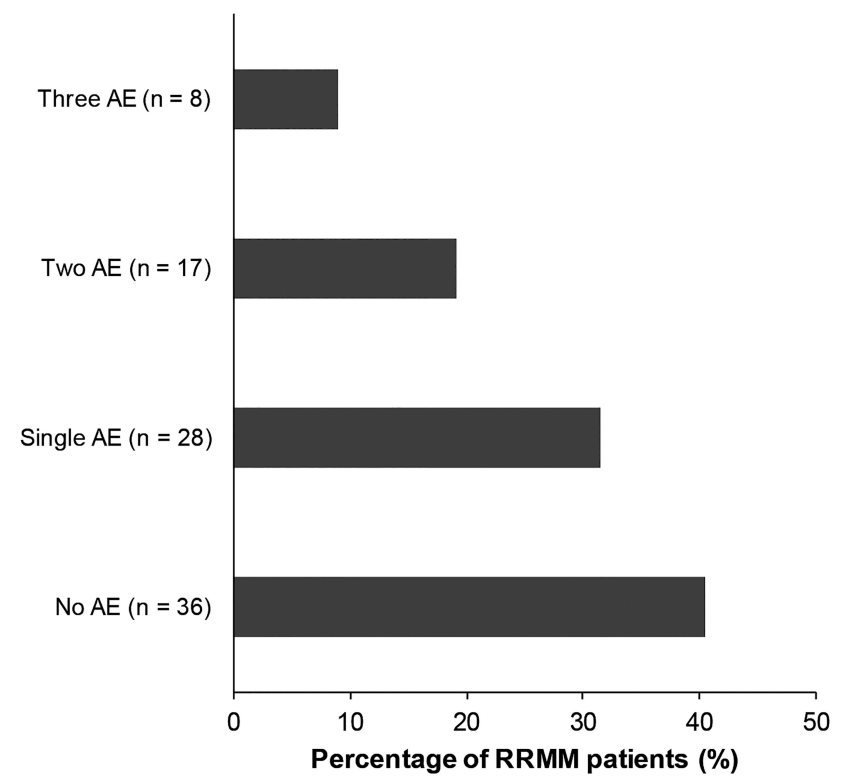

Figure 2 Percentage (\%) and number of patients (n) with no AE or presenting AE. Patients with $\mathrm{AE}$ presented I, 2, or 3 types of $\mathrm{AE}$.

Abbreviation: $A E$, adverse effects.
Lymphopenia was significantly associated with previous treatment lines before starting $\operatorname{DMF}(\mathrm{p}=0.042)$ and a longer time since MS onset (131 months vs 61.68; $\mathrm{p}=0.032$ ). A total of 7 patients developed grade 3 lymphopenia and 6 out of 7 patients had received previous therapies (INF $\beta$-1a, 3 patients; INF $\beta$-1b, 1 patient; TRF, 1 patient and laquinimod 1 patient). One patient who had been previously treated with GA developed mild lymphopenia and continued DMF treatment. All patients who developed grade 3 lymphopenia presented normal lymphocyte counts at DMF initiation (ranging from 1.25 to $\left.2.8 \times 10^{9} / \mathrm{L}\right)$. The association of lymphopenia with older age was close to statistical significance (46.5 vs 38.6 years; $\mathrm{p}=0.06$ ).

\section{Discussion}

The results of our study confirm that treatment with DMF is safe and effective in real-world clinical practice, both in patients who have previously followed other therapies and in patients in whom DMF was the first therapeutic option. Univariate analyses indicated that improvement in MRI data was associated with younger age, while improvement in the EDSS score was not associated with any study variables. These data seem to confirm that the overall effectiveness of DMF is not affected by the use of previous DMTs in our patient series.

Our data are completely consistent with the results of phase III and extension clinical trials on the efficacy of DMF. $^{20-24}$ In addition, we found that continuing DMF beyond 2 or 3 years still offers therapeutic benefit, confirming the findings of the previous studies.

Few direct comparative and real-world clinical practice studies have evaluated the effectiveness of different oral therapies on relapse rates and disability progression. Further scientific evidence is needed to support an optimal choice of therapy and dose escalation, and the most appropriate switch between alternative drugs.

A French comparative study showed a discontinuation rate for DMF of $8.5 \%$ due to a lack of effectiveness compared with $14.5 \%$ of patients who received TRF, while DMF achieved the best results in terms of radiological activity. However, after 2 years of treatment, $21 \%$ of patients treated with TRF reported AE compared with $16 \%$ of patients treated with DMF. ${ }^{31}$ Data from patient records have confirmed that DMF and FTY have similar efficacy in reducing ARR and EDSS. ${ }^{25,26}$ A more recent multicenter study that provides real-life data from a cohort of Spanish patients on treatment with DMF has described 
a $29 \%$ discontinuation rate, with GI effects and flushing accounting for discontinuation in $13.2 \%$ of patients. ${ }^{32}$

Although most patients receiving DMF show clinical improvement as evidenced by the physician and reported by the patients themselves, ${ }^{33} \mathrm{AE}$ are the primary cause of DMF discontinuation during the initial months. ${ }^{21,22,34}$ Mild-to-moderate GI AE are usually restricted to the first 2-4 weeks of treatment, and cause the highest dropout rate within the first 3 months. However, more than $80 \%$ of patients who remain on DMF during this period continue long-term treatment. ${ }^{35}$ AE management strategies such as symptomatic therapy and co-administration with food can mitigate these effects, and have been shown to reduce DMF dropout rates and increase medication persistence. $^{30,36,37}$

In our study, $87.6 \%$ of patients were still receiving DMF treatment at the final follow-up visit. In total, $58.9 \%$ of patients reported DMF-related AE (not associated with any of the study variables), most of which were already reported at the first scheduled 6-month visit. At the end of follow-up, we recorded a $13.5 \%$ dropout rate, with only $8.9 \%$ of patients discontinuing DMF because of AE but none did it due to GI AE or flushing. We recorded a dropout rate of only $3.8 \%$ due to lack of efficacy, which is among the lowest reported in a real-life study, despite the variability in study designs. ${ }^{33,37-40}$

DMF-related AE, especially GI AE and flushing, have been the main cause of lower patient adherence, as reported in several clinical and observational studies. ${ }^{41}$ The higher risk of relapse is clearly associated with nonadherence and thus, to MS-related hospitalizations and high related costs. ${ }^{42}$ For this reason, improved strategies designed to provide patients with better tools for selfmanagement of $\mathrm{AE}$ are not only critical to optimize therapeutic outcomes, but to reduce healthcare costs. ${ }^{37}$ Patient counseling regarding treatment outcomes and management of AE prior to starting DMF was a differential factor in our study design that may have contributed to improved adherence and dropout rates when compared to other real-life studies. The implications of these results are interesting, as prolonged use of DMF allows therapeutic benefits to be extended in the long term. In addition, the improved selfmanagement of $\mathrm{AE}$ correlated with a reduction in the use of healthcare services, as no AE-related phone calls or clinical visits were recorded during follow-up.

One of the risks of DMF treatment is the development of severe prolonged lymphopenia and an increased likelihood of infections, which are the most common reasons for hospitalization. ${ }^{43}$ In placebo-controlled trials, the mean white blood cell (WBC) count decreased by approximately $30 \%$ during the first year of treatment with DMF and then remained stable. WBC counts of $<0.5 \times 10^{9}$ lymphocytes/L were observed in $6 \%$ of patients with DMF and persisted for $\geq 6$ months in $2 \%$ of patients. Complete blood count monitoring is currently recommended before starting DMF treatment and every 3 months thereafter. In this respect, the ALC has been validated as an effective variable for monitoring and identifying patients at risk of moderate or severe lymphopenia. ${ }^{44,45}$ It has been observed that patients who experience a decrease in ALC $>38 \%$ after 3 months of treatment are approximately 6 times more likely to develop significant lymphopenia, and that ALC recovers slowly within 2 to 4 months of discontinuing DMF treatment in patients with prolonged lymphopenia. ${ }^{46,47}$

In our patient series, lymphopenia was the most frequent cause of treatment discontinuation (7.7\%), and was associated with the use of DMTs prior to treatment with DMF, as confirmed in studies with real-life data, ${ }^{48}$ and with a longer time since disease onset.

The incidence of lymphopenia with DMF has been associated with older age, ${ }^{32,49}$ which is in turn associated with lower lymphocyte counts. Accordingly, older MS patients are at higher risk of DMTs-induced lymphopenia. In our series, we observed a trend of association between the incidence of lymphopenia and older age, although it was not statistically significant (probably due to the small number of patients included in our study). A recent safety and effectiveness study, still underway, has suggested that in clinical practice, DMF remains beneficial in patients $\geq 55$ years. $^{50}$ However, it has been confirmed that in older patients, lymphocyte repopulation is much slower and has a longer duration after discontinuing DMF. ${ }^{49}$ Further studies are still needed to assess the safety and effectiveness of DMF treatment in older MS patients.

There are some limitations to this real-world study, including its retrospective and observational nature. The lack of stringent inclusion criteria may contribute to potential bias, while the limited number of patients reduces the power of the study and may explain the lack of significance in some statistical analyses. All patients included were treated in two hospitals in one geographic area. Thus, heterogeneities in data collection methods and inaccurate assessment of some clinical information cannot be ruled out and may have contributed to loss of further confounding factors; moreover, results may not be representative of 
the national RRMS population. These limitations mean that study findings need to be interpreted cautiously.

\section{Conclusions}

In our series, DMF was highly effective, both clinically and radiologically. Although $59 \%$ of the patients had AE, neither GI-related AE nor flushing - the most frequently reported $\mathrm{AE}$-were recorded as a reason for treatment discontinuation. Moreover, the development of lymphopenia was associated with previous use of other DMTs and a longer time since disease onset. The results of our study confirm that written information given to patients prior to treatment initiation creates more realistic expectations and promotes better tolerance to DMF and a reduction in faceto-face and/or telephone consultations, which could result in lower health costs.

\section{Acknowledgments}

The authors thank Dr. Susana Cañón, Medical Statistics Consulting S. L. (MSC) for the scientific writing of the manuscript and Biogen for providing us with this service.

\section{Funding}

This study has not been funded by any public or private body.

\section{Disclosure}

A. Rodríguez-Regal has received compensation from Genzyme, Roche, Novartis, Sanofi, Biogen and TEVA for services as consultant. L. Ramos-Rúa and C. AmigoJorrín have received compensation from Genzyme, Roche, Novartis and Biogen for service as consultants. L. Anibarro-García has received compensation from Genzyme for services as consultant. A. Lopez Real has received compensation from Genzyme, Roche, Biogen and TEVA for services as consultant. The authors report no other conflicts of interest in this work.

\section{References}

1. Ransohoff RM, Hafler DA, Lucchinetti CF. Multiple sclerosis - a quiet revolution. Nat Rev Neurol. 2015;11:134-142. doi:10.1038/ nrneurol.2015.14

2. Oh J, Vidal-Jordana A, Montalban X. Multiple sclerosis: clinical aspects. Curr Opin Neurol. 2018;31:752-759. doi:10.1097/ WCO.0000000000000622

3. Perez-Carmona N, Fernandez-Jover E, Sempere AP. [Epidemiology of multiple sclerosis in Spain]. Rev Neurol. 2019;69:32-38. doi: $10.33588 / \mathrm{rn} .6901 .2018477$
4. Weiner HL. Multiple sclerosis is an inflammatory T-cell-mediated autoimmune disease. Arch Neurol. 2004;61:1613-1615. doi:10.1001/ archneur.61.10.1613

5. Dendrou CA, Fugger L, Friese MA. Immunopathology of multiple sclerosis. Nat Rev Immunol. 2015;15:545-558. doi:10.1038/nri3871

6. Dobson R, Giovannoni G. Multiple sclerosis - a review. European J Neurol. 2019;26:27-40. doi:10.1111/ene.13819

7. Giovannoni G. Disease-modifying treatments for early and advanced multiple sclerosis: a new treatment paradigm. Curr Opin Neurol. 2018;31:233-243. doi:10.1097/WCO.0000000000000561

8. Wingerchuk DM, Weinshenker BG. Disease modifying therapies for relapsing multiple sclerosis. BMJ. 2016;354:i3518. doi:10.1136/bmj. i3518

9. Torkildsen O, Myhr KM, Bo L. Disease-modifying treatments for multiple sclerosis - a review of approved medications. European J Neurol. 2016;23(Suppl 1):18-27. doi:10.1111/ene.12883

10. Mehling M, Kappos L, Derfuss T. Fingolimod for multiple sclerosis: mechanism of action, clinical outcomes, and future directions. Curr Neurol Neurosci Rep. 2011;11:492-497. doi:10.1007/s11910-011-0216-9

11. Bar-Or A, Pachner A, Menguy-Vacheron F, et al. Teriflunomide and its mechanism of action in multiple sclerosis. Drugs. 2014;74:659-674. doi:10.1007/s40265-014-0212-x

12. Diebold M, Sievers C, Bantug G, et al. Dimethyl fumarate influences innate and adaptive immunity in multiple sclerosis. J Autoimmun. 2018;86:39-50. doi:10.1016/j.jaut.2017.09.009

13. Juanatey A, Blanco-Garcia L, Tellez N. Ocrelizumab: its efficacy and safety in multiple sclerosis. Rev Neurol. 2018;66:423-433.

14. Derfuss T, Mehling M, Papadopoulou A, et al. Advances in oral immunomodulating therapies in relapsing multiple sclerosis. Lancet Neurol. 2020;19:336-347. doi:10.1016/S1474-4422(19)30391-6

15. Naismith RT, Wundes A, Ziemssen T, et al. Diroximel fumarate demonstrates an improved gastrointestinal tolerability profile compared with dimethyl fumarate in patients with relapsing-remitting multiple sclerosis: results from the randomized, double-blind, phase III EVOLVE-MS-2 study. CNS Drugs. 2020;34:185-196. doi:10.1007/s40263-020-00700-0

16. Rae-Grant A, Day GS, Marrie RA, et al. Practice guideline recommendations summary: disease-modifying therapies for adults with multiple sclerosis: report of the guideline development, dissemination, and implementation subcommittee of the American Academy of Neurology. Neurology. 2018;90:777-788. doi:10.1212/WNL.000000 0000005347

17. Montalban X, Gold R, Thompson AJ, et al. ECTRIMS/EAN Guideline on the pharmacological treatment of people with multiple sclerosis. Mult Scler. 2018;24:96-120. doi:10.1177/1352458517751049

18. Linker RA, Lee DH, Ryan S, et al. Fumaric acid esters exert neuroprotective effects in neuroinflammation via activation of the Nrf2 antioxidant pathway. Brain. 2011;134:678-692. doi:10.1093/brain/awq386

19. Albrecht P, Bouchachia I, Goebels N, et al. Effects of dimethyl fumarate on neuroprotection and immunomodulation. J Neuroinflammation. 2012;9:163. doi:10.1186/1742-2094-9-163

20. Gold R, Kappos L, Arnold DL, et al. Placebo-controlled Phase 3 study of oral BG-12 for relapsing multiple sclerosis. $N$ Engl J Med. 2012;367:1098-1107. doi:10.1056/NEJMoa1114287

21. Fox RJ, Miller DH, Phillips JT, et al. Placebo-controlled phase 3 study of oral BG-12 or glatiramer in multiple sclerosis. $N$ Engl J Med. 2012;367:1087-1097. doi:10.1056/NEJMoa1206328

22. Gold R, Arnold DL, Bar-Or A, et al. Long-term effects of delayed-release dimethyl fumarate in multiple sclerosis: interim analysis of ENDORSE, a randomized extension study. Mult Scler. 2017;23:253-265. doi:10.1177/1352458516649037

23. Gold R, Giovannoni G, Phillips JT, et al. Sustained effect of delayed-release dimethyl fumarate in newly diagnosed patients with relapsing-remitting multiple sclerosis: 6-year interim results from an extension of the DEFINE and CONFIRM studies. Neurol Ther. 2016;5:45-57. doi:10.1007/s40120-016-0042-8 
24. Havrdova E, Giovannoni G, Gold R, et al. Effect of delayed-release dimethyl fumarate on no evidence of disease activity in relapsing-remitting multiple sclerosis: integrated analysis of the phase III DEFINE and CONFIRM studies. Eur $J$ Neurol. 2017;24:726-733. doi:10.1111/ene.13272

25. Boster A, Nicholas $\mathrm{J}, \mathrm{Wu} \mathrm{N}$, et al. Comparative effectiveness research of disease-modifying therapies for the management of multiple sclerosis: analysis of a large health insurance claims database. Neurol Ther. 2017;6:91-102. doi:10.1007/s40120-017-0064-x

26. Braune S, Grimm S, van Hovell P, et al. Comparative effectiveness of delayed-release dimethyl fumarate versus interferon, glatiramer acetate, teriflunomide, or fingolimod: results from the German NeuroTransData registry. J Neurol. 2018;265:2980-2992. doi:10.1007/s00415-018-9083-5

27. Rock M, Pike J, Jones E, et al. Reduced healthcare resource utilisation for patients treated with delayed release dimethyl fumarate versus injectable therapies: findings from a real-world cross-sectional study of MS patients. Value Health. 2018;21:S342. doi:10.1016/j.jval.2018.09.2045

28. Kalincik T, Kubala Havrdova E, Horakova D, et al. Comparison of fingolimod, dimethyl fumarate and teriflunomide for multiple sclerosis. J Neurol Neurosurg Psychiatry. 2019;90:458-468. doi:10.1136/jnnp-2018-319831

29. Dello Russo C, Scott KA, Pirmohamed M. Dimethyl fumarate induced lymphopenia in multiple sclerosis: A review of the literature. Pharmacol Ther. 2020;107710. doi:10.1016/j. pharmthera.2020.107710

30. Theodore Phillips J, Erwin AA, Agrella S, et al. Consensus management of gastrointestinal events associated with delayed-release dimethyl fumarate: a delphi study. Neurol Ther. 2015;4:137-146. doi:10.1007/s40120-015-0037-x

31. Laplaud DA, Casey R, Barbin L, et al. Comparative effectiveness of teriflunomide vs dimethyl fumarate in multiple sclerosis. Neurology. 2019;93:e635-e646. doi:10.1212/WNL.0000000000007938

32. Sabin J, Urtiaga S, Pilo B, et al. Tolerability and safety of dimethyl fumarate in relapsing multiple sclerosis: a prospective observational multicenter study in a real-life Spanish population. J Neurol. 2020;267:2362-2371. doi:10.1007/s00415-020-09848-7

33. Pandey K, Giles K, Balashov K. Safety and effectiveness of delayed-release dimethyl fumarate maintained over 4 years in multiple sclerosis patients treated in routine medical practice. Paper presented at: 35th Congress of the European Committee for Treatment \& Research in Multiple Sclerosis ECTRIMS 2019; Stockholm, Sweden.

34. Fox EJ, Vasquez A, Grainger W, et al. Gastrointestinal tolerability of delayed-release dimethyl fumarate in a multicenter, open-label study of patients with relapsing forms of multiple sclerosis (MANAGE). Int J MS Care. 2016;18:9-18. doi:10.7224/1537-2073.2014-101

35. Pandey K, Giles K, Jacques F, et al. Remaining on dimethyl fumarate for 3 months is associated with high rates of long-term treatment continuation in the clinical setting. Paper presented at: Consortium of Multiple Sclerosis Centers 2019; Seattle, WA

36. Min J, Cohan S, Alvarez E, et al. Real-world characterization of dimethyl fumarate-related gastrointestinal events in multiple sclerosis: management strategies to improve persistence on treatment and patient outcomes. Neurol Ther. 2019;8:109-119. doi:10.1007/s40120019-0127-2
37. Sejbaek T, Nybo M, Petersen T, Illes Z. Real-life persistence and tolerability with dimethyl fumarate. Mult Scler Relat Disord. 2018;24:42-46. doi:10.1016/j.msard.2018.05.007

38. Ernst FR, Barr P, Elmor R, Wong SL. Relapse outcomes, safety, and treatment patterns in patients diagnosed with relapsing-remitting multiple sclerosis and initiated on subcutaneous interferon $\beta-1 \mathrm{a}$ or dimethyl fumarate: a real-world study. Curr Med Res Opin. 2017;33:2099-2106. doi:10.1080/03007995.2017.1380616

39. Mallucci G, Annovazzi P, Miante S, et al. Two-year real-life efficacy, tolerability and safety of dimethyl fumarate in an Italian multicentre study. J Neurol. 2018;265:1850-1859. doi:10.1007/s00415-0188916-6

40. Allan M, Grant L. A retrospective analysis of real-world discontinuation rates with delayed-release dimethyl fumarate in patients with relapsing-remitting multiple sclerosis. Neurol Ther. 2020;9:85-92. doi:10.1007/s40120-019-00174-3

41. Narapureddy B, Dubey D. Clinical evaluation of dimethyl fumarate for the treatment of relapsing-remitting multiple sclerosis: efficacy, safety, patient experience and adherence. Patient Prefer Adherence. 2019;13:1655-1666. doi:10.2147/PPA.S187529

42. Tan H, Cai Q, Agarwal S, et al. Impact of adherence to disease-modifying therapies on clinical and economic outcomes among patients with multiple sclerosis. Adv Ther. 2011;28:51-61. doi:10.1007/s12325-010-0093-7

43. Maia C, Costa A, Abreu P, Sa MJ. All-cause hospitalizations in multiple sclerosis patients. Rev Neurol. 2019;68:229-235. doi:10.33588/rn.6806.2018281

44. Fox RJ, Chan A, Gold R, et al. Characterizing absolute lymphocyte count profiles in dimethyl fumarate-treated patients with MS: patient management considerations. Neurol Clin Pract. 2016;6:220-229. doi:10.1212/CPJ.0000000000000238

45. Mehta D, Miller C, Arnold DL, et al. Effect of dimethyl fumarate on lymphocytes in RRMS: implications for clinical practice. Neurology. 2019;92:e1724-e1738. doi:10.1212/WNL.0000000000007262

46. Sainz de la Maza S, Medina S, Villarrubia N, et al. Factors associated with dimethyl fumarate-induced lymphopenia. $J$ Neurol Sci. 2019;398:4-8. doi:10.1016/j.jns.2019.01.007

47. Chan A, Rose J, Alvarez E, et al. Lymphocyte reconstitution after DMF discontinuation in clinical trial and real-world patients with MS. Neurol Clin Pract. 2020. doi:10.1212/CPJ.0000000000000800

48. Longbrake EE, Naismith RT, Parks BJ. et al. Dimethyl fumarate-associated lymphopenia: risk factors and clinical significance. Mult Scler J Exp Transl Clin;2015. 1. doi: 10.1177/ 2055217315596994

49. Briner M, Bagnoud M, Miclea A, et al. Time course of lymphocyte repopulation after dimethyl fumarate-induced grade 3 lymphopenia: contribution of patient age. Ther Adv Neurol Disord. 2019;12:1756286419843450. doi:10.1177/1756286419843450

50. Mao-Draayer Y, Giles K, Balashov K. Safety and effectiveness of delayed-release dimethyl fumarate in patients $\geq 55$ years enrolled in the phase IV ESTEEM study Paper presented at: Consortium of Multiple Sclerosis Centers 2019; Seattle, WA. 


\section{Publish your work in this journal}

Patient Preference and Adherence is an international, peer-reviewed, open access journal that focusing on the growing importance of patient preference and adherence throughout the therapeutic continuum. Patient satisfaction, acceptability, quality of life, compliance, persistence and their role in developing new therapeutic modalities and compounds to optimize clinical outcomes for existing disease

states are major areas of interest for the journal. This journal has been accepted for indexing on PubMed Central. The manuscript management system is completely online and includes a very quick and fair peer-review system, which is all easy to use. Visit http:// www.dovepress.com/testimonials.php to read real quotes from published authors. 